\title{
Sağlık Bilimleri Fakültesi Öğrencilerinin Premenstrual Sendrom ile Baş Etmede Kullandığı Geleneksel ve Tamamlayıcı Tıp Uygulamaları*
}

\section{Traditional and Complementary Medicine Applications Used by Health Sciences Students in Coping with}

Premenstrual Syndrome

\section{Didem Şimşek Küçükkelepçei, Fatma Nur Dumanii, Zehra Gölbaş̧ii}

iDr. Öğr. Üyesi, Lokman Hekim Üniversitesi, Sağlık Bilimleri Fakültesi, Ebelik AD. https://orcid.org/0000-0003-0001-2581

iiArş. Gör., Lokman Hekim Üniversitesi, Sağlık Bilimleri Fakültesi, Doğum ve Kadın Hastalıkları Hemşireliği AD. https://orcid.org/0000-0001-9736-2769

iiiProf. Dr., Lokman Hekim Üniversitesi, Sağlık Bilimleri Fakültesi, Doğum ve Kadın Hastalıkları Hemşireliği AD. https://orcid.org/0000-0002-0410-7433

öz

Amaç: Sağlık Bilimleri Fakültesi öğrencilerinin premenstrual semptomlar ile baş etmede kullandığı geleneksel ve tamamlayıcı tıp uygulamalarını belirlemektir.

Yöntem: Araştırma tanımlayıcı tipte olup, Ankara'da bir vakıf üniversitesinin sağlık bilimleri fakültesinde öğrenime devam eden kadın öğrenciler ile 27 Mayıs - 6 Ağustos tarihleri arasında yürütüldü. Araştırmanın örneklemini çalışmaya katılmaya gönüllü olan ve formları tam dolduran 154 kadın öğrenci oluşturdu. Verilerin toplanmasında, kişisel bilgi formu ve Premenstrual Sendrom Ölçeği (PMSÖ) uygulandı. Araştırma verileri IBM SPSS 25 programı ile değerlendirildi. Araştırmanın analizinde sayı, yüzde, ortalamaıstandart sapma, minimum ve maksimum değerler gibi tanımlayıcı istatistikler, Kolmogorov-Smirnov testi, Kruskal Wallis Varyans Analizi ve Mann Whitney U testi kullanıldı. Bulgular: Öğrencilerin PMS prevalansının \%80,5 olduğu bulundu. Öğrencilerin geleneksel ve tamamlayıcı tıp uygulamaları olarak, bitkisel tedaviler ve vitamin desteğinden en çok vitamin desteği yöntemini $(\% 20,8)$; vücut terapilerinden en çok masaj yöntemini $(\% 61,7)$; zihin ve beden tekniklerinden en fazla müzik dinlemek yöntemini (\%72,1); sıcak uygulama tekniklerinden en fazla karın bölgesine sıcak uygulama yöntemini $(\% 86,4)$ kullandıkları belirlendi.

Sonuç: Öğrencilerin büyük bir çoğunluğunun premenstrual semptomları yaşadığı belirlendi. Öğrencilerin premenstrual semptomlarla baş etmede birbirinden farklı geleneksel ve tamamlayıcı tıp uygulamalarını kullandıkları belirlendi.

Anahtar Kelimeler: Geleneksel ve tamamlayııı tıp, Öğrenci, Premenstrual semptom, PMS, Hemşirelik.

\section{ABSTRACT}

Objective: This research amis to determine the traditional and complementary medicine practices used by the students of the Faculty of Health Sciences to cope with premenstrual symptoms.

Methods: The research is descriptive and was conducted with female students studying at the health sciences faculty of a foundation university in Ankara between 27 May and 6 August. The sample of the study consisted of 154 female students who volunteered to participate in the study and filled out the forms completely. Personal information form and Premenstrual Syndrome Scale (PMSS) were used to collect data. Research data were evaluated with IBM SPSS 25 program. Descriptive statistics such as number, percentage, mean \pm standard deviation, minimum and maximum values, Kolmogorov-Smirnov test, Kruskal Wallis Analysis of Variance and Mann Whitney $\mathrm{U}$ test were used in the analysis of the study.

Results: It was found that the PMS prevalence of the students was $80.5 \%$. As traditional and complementary medicine practices of the students, the most common method of vitamin support among herbal treatments and vitamin supplement (20.8\%); massage method mostly (61.7\%) among body therapies; listening to music mostly among mind and body techniques (72.1\%); It was determined that they mostly used the hot application method (86.4\%) on the abdominal region among the hot application techniques.

Conclusion: It was determined that the majority of the students showed the presence of premenstrual symptoms. It was found that the students used the method of applying heat to the abdomen the most and the acupuncture method the least as traditional and complementary medicine practices.

Keywords: Traditional and complementary medicine, Student, Premenstrual symptom, PMS, Nursing.

\author{
*Mersin Üniversitesi Tıp Fakültesi Lokman Hekim Tıp Tarihi ve Folklorik Tıp Dergisi, 2022; 12 (1): 116-125 \\ DOI: $10.31020 /$ mutftd.984778 \\ e-ISSN: 1309-8004, ISSN 1309-761X \\ Geliş Tarihi - Received: 19 Ağustos 2021; Kabul Tarihi - Accepted: 09 Kasım 2021 \\ Iletişim - Correspondence Author: Fatma Nur Duman <fatmanurduman8@gmail.com> \\ Etik Kurul Onayı: Lokman Hekim Üniversitesi Girişimsel Olmayan Etik Kurulu (27.04.2021 tarih, 2021/059 sayı)
}




\section{Giriş}

Menstruasyon, menarşla başlayarak aylık periyotlar halinde devam edip, menopozla sonlanan ve kadın yaşamının yaklaşık 30-35 yıllık süresini kapsayan, kanama ve hormonal değişiklik ile karakterize, bütün sistemi etkileyen, fizyolojik bir süreçtir. ${ }^{1,2}$ Menstruasyon, fizyolojik bir süreç olmasına rağmen, pek çok faktörden etkilenmektedir. Bu faktörlerden biri de kültürdür. Bazı kültürlerde, menstruasyon kadınlığa geçiş ve doğurganlık gibi olumlu bir durum olarak nitelendirilirken bazı kültürlerde ise ağrı ve stres yaratan, hatta hastalık sayılabilen olumsuz bir durum olarak nitelendirilmektedir. Menstruasyonun olumsuz bir durum olarak algılandığı kültürlerde menstruasyona yönelik gelişen tutumun sonucunda psikososyal problemler yaşanabilmektedir. ${ }^{3}$ Menstruasyonda meydana gelen değişikliklere bakıldığında karşımıza menstrual düzensizlikler, premenstrual sendrom (PMS) ve dismenore gibi problemler çıkmaktadır. PMS, menstrual siklusunun geç luteal fazında, menstruasyondan bir ila on dört gün öncesinde ortaya çıkan ve şiddeti gün geçtikçe artan, menstruasyonun başlamasıyla kısa bir süre içinde hafifleyerek sonlanan, fiziksel, ruhsal ve davranışsal farklıııların yaşandığı bir süreçtir. PMS'nin etiyolojisi tam olarak bilinmemesine rağmen, yaygın olan görüşün, dolaşımdaki üreme hormonlarının düzeylerindeki dalgalanmalara karşı vücudun gösterdiği tepkiler olduğu ifade edilmektedir. ${ }^{4}$ PMS'nin, yaşanma durumu ve şiddeti kişiden kişiye göre farklıık göstermekle birlikte; memelerde hassasiyet/dolgunluk, abdominal şişkinlik, eklem ve kas ağrısı, konstipasyon, diyare, mide bulantısı, akne, sıcak basması, baş ağrısı, kilo artışı, iştahta değişiklik gibi fiziksel belirtiler; cinsel istekte değişiklik, çalışma alışkanlığında değişiklik, insan ilişkilerinden kaçınma, kavgaya eğilim ve ağlama nöbetleri, uyku bozuklukları, yoğunlaşma güçlüğü, ilgisizlik, sosyal içe kapanma gibi davranışsal belirtiler; kızgınlık, anksiyete, huzursuzluk, yetersizlik hissi, yalnızlık, unutkanlık, suçluluk hissi, sinirlilik, paranoya, ses ve ışığa aşırı duyarlılık, intihar düşüncesi, psikoz, değişken ruh hali, depresif ruh hali, kontrolü kaybetme hissi, konsantrasyonda azalma, konfüzyon, öz saygıda azalma gibi psikolojik belirtiler olacak şekilde çok sayıda semptomu olduğu belirtilmektedir. ${ }^{1}$

Premenstrual semptomların yönetiminde hem farmakolojik hem de nonfarmakolojik pek çok yöntem kullanılmaktadır. Farmakolojik ajanlara bakıldığında; progesteron tedavisi, oral kontraseptifler, danazol tedavisi, gonodotropin releasing hormon antagonistleri, kalsiyum, magnezyum tedavisi, analjezikler, anksiyolitikler ve antidepresanların kullanıldığı görülmektedir. Ancak kullanılan farmakolojik ajanların yorgunluk, baş ağrısı, duygu durumunda değişiklik ve gastrointestinal kanama gibi komplikasyonları ortaya çıkabilmektedir. ${ }^{5}$ Komplikasyonların görülmesiyle kadınlar; farmakolojik yöntemlere göre daha güvenilir olması, kullanımının daha kolay olması, rahatlıkla erişilebilmesi, daha az komplikasyona sahip olması ve farmakolojik yöntemlerin ortaya çıkardığı ekonomik yükü azaltması gibi nedenleriyle geleneksel ve tamamlayıı tıp olarak da adlandırılan nonfarmakolojik yöntemleri tercih edebilmektedir. Dünya Sağlık Örgütü’ne göre geleneksel ve tamamlayıcı tıp “fiziksel ve psikiyatrik hastalıklardan korunma, bunlara tanı koyma, hastalıkları tedavi etmenin yanında tam iyilik hali olarak nitelendirilen sağlığın sürdürülmesinde de kullanılan, farklı kültürlere ve geleneklere özgü teori, inanç ve tecrübelere dayalı-izahı yapılabilen veya yapılamayan bilgi, beceri, tutum ve uygulamalar bütünü olarak tanımlanmaktadır. ${ }^{6}$ Premenstrual semptomların yönetiminde faydalanılan bu uygulamalara bakıldığında; bilişsel davranışsal tedavi, refleksoloji, yoga, masaj, egzersiz, aromaterapi, kayropraksi, fitoterapi ve akupunktur gibi yöntemlerin kullanıldığı görülmektedir. ${ }^{7-10}$ Literatürde genç kadınların premenstrual yakınmalarının sık olduğu (\%50,2; $\% 54,0 ; \% 57,4)$ ancak tıbbi tedavi alma oranlarının düşük olduğu ve menstruasyon konusunda bilgilerinin yetersiz olduğu bildirilmiştir., ${ }^{711,12}$ Genç kadınların menstrual siklus konusunda bilgilendirilmesinin, menstruasyon hakkında olumlu tutum geliştirmelerine yardım edilmesinin, baş etme yöntemlerinin belirlenmesinin ve etkili metotların öğretilmesinin yaşanan sorunların azaltılması açısından önemli olduğu ve bu baş etme metotları arasında geleneksel ve tamamlayıcı tıp uygulamalarının kullanılmasının PMS yaşayan kadınlara öncelikli olarak önerilmesi gerektiği düşünülmektedir. ${ }^{2,12}$ 
Dünyada ve Türkiye'de premenstrual dönemde kadınların deneyimlediği sağılı sorunları, yaşam kaliteleri, bu dönemdeki rahatsızıkları azaltmak için yapılan uygulamalar ile ilgili çeşitli çalışmalar olmakla beraber ${ }^{3,9}$ bu dönemde kadınların başvurduğu ya da tercih ettiği geleneksel ve tamamlayıcı tıp uygulamalarının kullanımlarını inceleyen araştırmalar daha kısıtıdır.

Tüm bu kapsamda, bu araştırmanın amacı; Sağlık Bilimleri Fakültesi öğrencilerinin premenstrual semptomlar ile baş etmede kullandığı geleneksel ve tamamlayıcı tıp uygulamalarını belirlemektir.

\section{Gereç ve Yöntem}

\section{Araştırma Tasarımı ve Örneklemi}

Araştırma, tanımlayıcı tipte tasarlanmış ve 27 Mayıs-6 Ağustos 2021 tarihleri arasında Lokman Hekim Üniversitesi'nde gerçekleştirilmiştir. Araştırmanın evrenini Lokman Hekim Üniversitesi Sağlık Bilimleri Fakültesi'nde öğrenim gören 452 kadın öğrenci oluşturmuştur. Araştırmada örneklem seçimine gidilmeyerek evrenin tamamına ulaşılması amaçlanmıştır. Ancak araştırmanın örneklemini, araştırmaya katılmaya gönüllü olan ve formları eksiksiz dolduran 154 öğrenci oluşturmuştur.

\section{Veri Toplama Araçları}

Araştırmada veriler, kişisel bilgi formu ve Premenstrual Sendrom Ölçeği (PMSÖ) kullanılarak toplanmıştır.

Kişisel Bilgi Formu; araştırmacılar tarafından literatür taranarak oluşturulmuştur. Form katılımcıların sosyodemografik özelliklerini, menstrual özelliklerini ve PMS ile baş etmede kullandıkları geleneksel ve tamamlayıcı tıp uygulamalarına (bitkisel tedaviler, vitamin desteği, vücut terapileri, zihin ve beden teknikleri, sıcak uygulama) ilişkin verileri tanılayan 24 sorudan oluşmaktadır. ${ }^{15,16}$

Premenstrual Sendrom Ölçeği (PMSÖ); Gençdoğan tarafından 2006 yılında geliştirilen, premenstrual semptomların şiddetini ölçen, beşli likert tipte, 44 madde içeren Depresif Duygulanım, Anksiyete, Yorgunluk, Sinirlilik, Depresif Düşünceler, Ağrı, İştah Değişimleri, Uyku değişimleri ve Şişkinlik olmak üzere toplam dokuz alt boyuttan oluşan bir ölçektir. ${ }^{2}$ Ölçekte puanlama yapılırken "Sürekli" 5 puan, "Sık sık" 4 puan, "Bazen" 3 puan, "Çok az" 2 puan ve "Hiç" 1 puan olarak skorlanmakta, toplam puan üzerinden değerlendirilmektedir. Ölçeğin uygulanması, kişinin geriye dönük olarak "menstruasyon kanamasından bir hafta önceki süre içinde olma" durumu düşünülerek değerlendirmesi ile yapılmaktadır. Ölçekten en düşük 44, en yüksek 220 puan alınabilmektedir. Puan yükseldikçe PMS belirtilerinin şiddeti fazla olarak değerlendirilmektedir. Kişinin, PMS ölçeğinde toplam ölçek puanının (220) \%50'sini (110'nu) geçmesi durumunda PMS "var" olarak değerlendirilmektedir. Ölçeğin güvenirlilik çalışmasında Cronbach Alfa değeri 0.75 olarak bulunmuştur. ${ }^{2} \mathrm{Bu}$ araştırmada ölçeğin Cronbach Alfa değeri ise 0,96 olarak bulunmuştur.

\section{Verilerin Toplanması ve Analizi}

Veri toplama araçları Google Forms aracılığı ile çevrimiçi hale dönüştürülmüş, oluşturulan çevrimiçi link whatsApp ve e-posta yolu ile öğrencilere ulaştırılmıştır. Araştırmadan elde edilen veriler IBM SPSS 25 paket programı ile değerlendirilmiştir. Araştırmadan elde edilen verilerin analizinde; sayı, yüzde, ortalama sstandart sapma, minimum ve maksimum değerler gibi tanımlayıcı istatistikler, Kolmogorov-Smirnov testi, Kruskal Wallis Varyans Analizi ve Mann Whitney U testi kullanılmıştır.

\section{Araştırmanın Etik Yönü}

Araştırmaya başlamadan önce, Lokman Hekim Üniversitesi Girişimsel Olmayan Etik Kurulu'ndan etik kurul izni (Tarih:27/05/2021, Karar No:2021/059, Kod No:2021061), fakülte dekanlığından kurum izni ve öğrencilerden formlar uygulanmadan önce bilgilendirilmiş gönüllü onam formu alınmıştır. Araştırmanın tüm aşamalarında Helsinki Deklarasyonu Prensipleri'ne, Araştırma ve Yayın Etiği'ne uyulmuştur. 


\section{Bulgular}

Tablo 1'de öğrencilerin bazı demografik özellikleri ve menstruasyona ilişkin bilgileri bulunmaktadır. Öğrencilerin yaş ortalaması $20,36 \pm 1,47$; ortalama menarş yaşı $13,16 \pm 1,38$ ve ortalama menstruasyon süresi $5,63 \pm 1,23$ olarak bulunmuştur. Öğrencilerin $\% 29,9$ 'u hemşirelik bölümünde, $\% 38,1^{\prime} i$ 1.sınıf öğrencisidir.

Tablo 1. Demografik ve Menstruasyona İlişkin Özellikler ( $n=154)$

\begin{tabular}{|c|c|c|c|}
\hline \multicolumn{2}{|l|}{ Özellikler } & $\mathrm{X} \pm \mathrm{SS}$ & Min-Max \\
\hline \multicolumn{2}{|l|}{ Yaş } & $20,36 \pm 1,47$ & $18-29$ \\
\hline \multicolumn{2}{|l|}{ Menarş Yaşı } & $13,16 \pm 1,38$ & $10-22$ \\
\hline \multicolumn{2}{|l|}{ Menstruasyon Süresi } & $5,63 \pm 1,23$ & $1-8$ \\
\hline & & $\mathbf{n}$ & $\%$ \\
\hline \multirow[t]{4}{*}{ Bölüm } & Fizyoterapi ve Rehabilitasyon & 33 & 21,4 \\
\hline & Beslenme ve Diyetetik & 35 & 22,7 \\
\hline & Ebelik & 40 & 26,0 \\
\hline & Hemşirelik & 46 & 29,9 \\
\hline \multirow[t]{4}{*}{ Sinıf } & 1.sınıf & 59 & 38,3 \\
\hline & 2.sınıf & 54 & 35,1 \\
\hline & 3.sinıf & 35 & 22,7 \\
\hline & 4.sınıf & 6 & 3,9 \\
\hline \multirow{2}{*}{$\begin{array}{l}\text { Aile Üyelerinde Menstruasyonla İgili } \\
\text { Sorun Yaşayan Birey Varlığı }\end{array}$} & Var & 77 & 50,0 \\
\hline & Yok & 77 & 50,0 \\
\hline \multirow[t]{3}{*}{ Menstruasyon Düzeni } & Düzenli & 77 & 50,0 \\
\hline & Bazen Düzenli, Bazen Düzensiz & 63 & 40,9 \\
\hline & Düzensiz & 14 & 9,1 \\
\hline
\end{tabular}

Tablo 2'de öğrencilerin PMSÖ alt boyut ve toplam puan ortalamaları bulunmaktadır. Öğrencilerin PMSÖ toplam puan ortalaması $139,16 \pm 34,00$ olup, $\% 80,5^{\prime}$ inin premenstrual sendrom yaşadıkları bulunmuştur.

Tablo 2. PMSÖ Alt Boyut ve Toplam Puan Ortalamaları

\begin{tabular}{lrr}
\hline & $\mathbf{X} \pm \mathbf{S S}$ & Min-Max \\
\hline PMSÖ Toplam Puan & $139,16 \pm 34,00$ & $60-211$ \\
Depresif Duygulanım & $23,55 \pm 6,34$ & $7-35$ \\
Anksiyete & $18,06 \pm 6,68$ & $7-35$ \\
Yorgunluk & $21,48 \pm 5,58$ & $6-30$ \\
Sinirlilik & $17,22 \pm 5,16$ & $6-25$ \\
Depresif Düşünceler & $20,89 \pm 7,36$ & $7-35$ \\
Ağrı & $9,61 \pm 3,30$ & $3-15$ \\
Iş̧tah Değişimleri & $9,77 \pm 3,14$ & $3-15$ \\
Uyku Değişimleri & $8,40 \pm 3,13$ & $3-(14)$ \\
Şişkinlik & $\mathbf{n}$ & $3-15$ \\
\hline & $\mathbf{n}$ & $\mathbf{1 2 4}$ \\
\hline PMSÖ Puanı > Toplam Puanın \%50'si & 80,5 \\
\hline
\end{tabular}

Tablo 3'te öğrencilerin PMSÖ toplam puanlarının demografik ve menstruasyona ilişkin özelliklerine göre dağılımı yer almaktadır. Öğrencilerin; bölümlerine, sınıflarına ve menstruasyon düzenleri ile PMSÖ toplam puan ortalaması arasında istatistiksel olarak anlamlı fark bulunmamıştır $(p>0,05)$. Öğrencilerin, ailelerinde menstruasyonla ilgili sorun yaşayan birey varlığı değişkeni ile PMSÖ toplam puan ortalaması arasında istatistiksel olarak anlamlı fark bulunmuştur. Bu istatistiksel farklılığın hangi gruptan kaynaklandığını belirlemek amacıyla verilerin ikili analizi yapılmıştır. Ailelerinde menstruasyonla ilgili sorun yaşayan öğrencilerin PMSÖ toplam puan ortalaması, sorun yaşamayan öğrencilere nazaran daha yüksek bulunmuştur $(Z=-2,083 ; p=0,037<0,05)$. 
Tablo 3. Öğrencilerin PMSÖ Toplam Puanlarının Demografik ve Menstruasyona İlişkin Özelliklerine Göre Dağılımı

\begin{tabular}{|c|c|c|c|c|c|}
\hline Özellikler & & $n$ & $x^{2}$ & $p$ & $\mathbf{Z}$ \\
\hline \multirow[t]{4}{*}{ Bölüm } & Fizyoterapi ve Rehabilitasyon & 33 & 2,268 & 0,519 & \\
\hline & Beslenme ve Diyetetik & 35 & & & \\
\hline & Ebelik & 40 & & & \\
\hline & Hemşirelik & 46 & & & \\
\hline \multirow[t]{4}{*}{ Sinıf } & 1.sınıf & 59 & 0,976 & 0,807 & \\
\hline & 2.sınıf & 54 & & & \\
\hline & 3.sınıf & 35 & & & \\
\hline & 4.sınıf & 6 & & & \\
\hline Aile Üyelerinde Menstruasyonla İlgili & Var & 77 & 4,341 & 0,037 & $-2,083$ \\
\hline Sorun Yaşayan Birey Varlığı & Yok & 77 & & & \\
\hline \multirow[t]{3}{*}{ Menstruasyon Düzeni } & Düzenli & 77 & 0,725 & 0,696 & \\
\hline & Bazen Düzenli, Bazen Düzensiz & 63 & & & \\
\hline & Düzensiz & 14 & & & \\
\hline
\end{tabular}

Tablo 4'te öğrencilerin geleneksel ve tamamlayıcı tıp (GETAT) uygulamaları kullanma ve yararlılık durumları yer almaktadır. Araştırmaya katılan öğrenciler bitkisel tedaviler ve vitamin desteği grubundan en çok vitamin desteğini $(\% 20,8)$ kullanmakta olup, kullananların \%84,3'ünün yarar gördüğü bulunmuştur. Öğrenciler en az gül çayı $(\% 2,6)$ kullanmışlardır. Öğrenciler, vücut terapilerinden en çok masajı $(\% 61,7)$ kullanmakta olup, kullananların \%97,8'i yarar görmüştür. Öğrenciler en az akupunktur $(\% 0,6)$ yöntemini kullanmışlardır. Öğrenciler, zihin ve beden tekniklerinden en fazla müzik dinlemek $(\% 72,1)$ yöntemini kullanmakta olup, kullananların \%75,6'sı yarar görmüştür. Öğrenciler en az hipnoz tekniğini $(\% 3,2)$ kullanmışlardır. Öğrencilerin \%87,7'sinin sıcak uygulama yöntemi olarak karın bölgesine sıcak uygulama yaptığı, \%86,4'ünün ise duş yöntemini kullandığı bulunmuştur. Karın bölgesine sıcak uygulama yapan öğrencilerin \%88,7'sinin yarar gördüğü belirlenmiştir.

\begin{tabular}{|c|c|c|c|c|c|c|c|c|}
\hline \multirow[t]{3}{*}{ GETAT Uygulamaları } & \multicolumn{4}{|c|}{ Kullanma Durumu } & \multicolumn{4}{|c|}{ Yararlılık Durumu } \\
\hline & \multicolumn{2}{|c|}{ Kullanıyorum } & \multicolumn{2}{|c|}{ Kullanmıyorum } & \multicolumn{2}{|c|}{ Yararı Oldu } & \multicolumn{2}{|c|}{ Yararı Olmadı } \\
\hline & $\mathbf{n}$ & $\%$ & $\mathbf{n}$ & $\%$ & $\mathbf{n}$ & $\%$ & $\mathbf{n}$ & $\%$ \\
\hline \multicolumn{9}{|c|}{ Bitkisel Tedaviler ve Vitamin Desteği } \\
\hline Gül Çayı & 4 & 2,6 & 150 & 97,6 & 2 & 50,0 & 2 & 50,0 \\
\hline Karın Bölgesine Zeytinyağı & 12 & 7,8 & 142 & 92,2 & 12 & 100 & 0 & 0 \\
\hline \multicolumn{9}{|l|}{ Sürmek } \\
\hline Rezene Çayı & 13 & 8,4 & 141 & 91,6 & 11 & 84,0 & 2 & 15,4 \\
\hline Vitamin Desteği & 32 & 20,8 & 122 & 79,2 & 27 & 84,3 & 5 & 15,7 \\
\hline \multicolumn{9}{|l|}{ Vücut Terapileri } \\
\hline Akupunktur & 1 & 0,6 & 153 & 99,4 & 1 & 100 & 0 & 0 \\
\hline Refleksoloji & 5 & 3,2 & 149 & 96,8 & 5 & 100 & 0 & 0 \\
\hline Akupresür & 6 & 3,9 & 148 & 96,1 & 4 & 66,2 & 2 & 33,8 \\
\hline Fitoterapi (Bitkisel Ürün) & 36 & 23,4 & 118 & 76,6 & 30 & 83,3 & 6 & 16,7 \\
\hline Masaj & 95 & 61,7 & 59 & 38,3 & 93 & 97,8 & 2 & 2,2 \\
\hline \multicolumn{9}{|l|}{ Zihin ve Beden Teknikleri } \\
\hline Hipnoz & 5 & 3,2 & 149 & 96,8 & 5 & 100 & 0 & 0 \\
\hline Yoga & 30 & 19,5 & 124 & 80,5 & 26 & 86,6 & 4 & 13,4 \\
\hline Gevşeme Egzersizi & 82 & 53,2 & 72 & 46,8 & 78 & 95,1 & 4 & 4,9 \\
\hline Fiziksel & 100 & 64,9 & 54 & 35,1 & 92 & 92,0 & 8 & 8,0 \\
\hline \multicolumn{9}{|l|}{ Egzersiz/Spor/Yürüyüş } \\
\hline Dua & 104 & 67,5 & 50 & 32,5 & 91 & 87,5 & 13 & 12,5 \\
\hline Müzik Dinlemek & 111 & 72,1 & 43 & 27,9 & 84 & 75,6 & 27 & 24,4 \\
\hline \multicolumn{9}{|l|}{ Sicak Uygulama } \\
\hline Karın Bölgesine Sıcak & 135 & 87,7 & 19 & 12,3 & 127 & 94,0 & 8 & 6,0 \\
\hline \multicolumn{9}{|l|}{ Uygulama } \\
\hline Duş & 133 & 86,4 & 21 & 13,6 & 118 & 88,7 & 15 & 11,3 \\
\hline
\end{tabular}




\section{Tartışma}

Çalışmamız, üniversite öğrencilerinde PMS prevalansını saptamak ve öğrencilerin PMS ile baş etmede kullandığı geleneksel ve tamamlayııı tıp uygulamalarını belirlemek amacıyla yapılmıştır.

Çalışmamızda PMS yaşayan öğrencilerin oranı \%80,5 olarak bulunmuştur. Hemşirelik öğrencilerinde PMS prevalansının belirlenmesi amacıyla yapılmış çalışmalarda PMS prevalansının \%50,2 ile \%70,7 arasında değiştiği saptanmıştır. ${ }^{11,13-15}$ Açıkgöz ve arkadaşlarının yaptıkları çalışmada üniversite birinci sınıf öğrencileri arasında PMS prevalansı \%58,1, Aba ve arkadaşlarının yaptıkları çalışmada, genç kadınlarda PMS görülme oranı $\% 65,2$ olarak belirlenmiştir. ${ }^{19,20}$ Shammani ve arkadaşlarının yaptıkları çalışmada tıp öğrencileri arasında PMS görülme sıklığı \%65, Bhuvaneswari ve arkadaşlarının yaptıkları çalışmada üniversite öğrencileri arasında PMS prevalansı \%62,7 olarak bulunmuştır. ${ }^{21,22}$ Bizim sonuçlarımız ile literatürdeki sonuçların farklı olmasının nedeninin çalışılan yaş ve meslek grubu, evren ve örneklem değişiklikleri olduğu, ayrıca öğrencilerin kişisel yaşam biçimi, beslenme şekilleri, stres gibi birçok faktörün bu farklılık üzerinde etkisi olduğu düşünülmektedir.

Çalışmamızda PMS yaşayan öğrencilerin PMSÖ’den ortalama 139,16 $\pm 34,00$ puan aldıkları ve PMS belirtileri yaşama yoğunluğunun orta düzeyin üzerinde olduğu saptanmıştır. Çağlar ve Yeşiltepe Oskay'ın yaptıkları çalışmada, öğrencilerin PMSÖ toplam puan ortalaması 128.61士33.68, Topatan ve Kahraman'ın üniversite öğrencileri üzerinde yaptıkları çalışmada, öğrencilerin PMSÖ toplam puan ortalaması $118.4 \pm 32.4$, Aba ve arkadaşlarının genç kadınlar üzerinde yaptıkları çalışmada, kadınların PMSÖ toplam puan ortalaması 122.14 \pm 32.60 olduğu saptanmıştır. ${ }^{16,17,20}$ Çalışma sonucumuzda elde ettiğimiz PMSÖ toplam puan ortalaması ile literatürdeki sonuçlar benzer aralıkta olsa da PMSÖ puanlarındaki farklılıklara; katılımcıların kişisel yaşam biçimi, beslenme şekilleri, stres gibi birçok faktörün neden olabileceği düşünülmektedir.

Çalışma sonucumuzda öğrencilerin, ailede menstruasyonla ilgili sorun yaşayan birey varlığı değişkenine göre PMSÖ toplam puan ortalaması arasında istatistiksel olarak anlamlı fark bulunmuştur. Ailelerinde menstruasyonla ilgili sorun yaşayan öğrencilerin PMSÖ toplam puan ortalaması, sorun yaşamayan öğrencilere nazaran daha yüksek bulunmuştur. Paralel olarak; Bhuvaneswari ve arkadaşlarının yaptıkları çalışmada, ailelerinde menstruasyonla ilgili sorun yaşayan birey olan öğrencilerin PMSÖ toplam puan ortalaması, olmayanlara göre anlamlı şekilde daha yüksek bulunmuştur. ${ }^{22} \mathrm{Bu}$ durum, premenstrual semptomların genetik geçişli ya da öğrenilmiş bir davranış olabileceği şeklinde yorumlanabilir. Sonuçlarımızın aksine; Çağlar ve Oskay'ın hemşirelik öğrencilerinde; Erbaş ve Altunbaş’ın lise öğrencilerinde yaptıkları çalışmada, öğrencilerin anne ya da kız kardeşlerinin PMS semptomları yaşamaları ile PMSÖ puan ortalaması arasında anlamlı fark bulunmamıştır. ${ }^{16,24}$ Bizım sonuçlarımız ile literatürdeki sonuçların farklı olmasının nedeninin araştırmamızın örneklem grubunun yaş ortalamasından ve örneklem grubumuzun sayısının az olmasından kaynaklandığı düşünülmektedir.

Araştırmamıza katılan öğrencilerin PMS'nin yönetiminde; bitkisel tedaviler ve vitamin desteği grubundan en fazla vitamin desteğini kullandığı, kullananların \%84,3'ünün yarar sağladığı bulunmuştur. Bahrami ve arkadaşlarının yapmış olduğu randomize kontrollü çalışmada dokuz hafta boyunca $D$ vitamini içeren kapsül kullanan müdahale grubunda PMS görülme sıklığının \%10.1 azaldığı bildirilmiştir. ${ }^{25}$ Dadkhah ve arkadaşlarının yaptığı randomize kontrollü çalışmada iki ay boyunca $\mathrm{E}$ vitamini içeren kapsül kullanan müdahale grubunda PMS görülme sıklığının \%15,6; D vitamini içeren kapsül kullanan müdahale grubunda \%11,9 azaldığı belirtilmiştir. ${ }^{26}$ Karimi ve arkadaşlarının genç kadınlarla yaptığı çalışmada $D$ vitamini kullanan deney grubundaki kadınların PMS semptomlarının azaldığı bildirilmiştir. ${ }^{27}$ Bu noktada vitamin desteğinin PMS semptomların yönetiminde etkili olduğu literatürdeki çalışmalar ile desteklenmektedir. Çalışmamızda öğrencilerin en az $(\% 2,6)$ gül çayı tükettikleri bulunmuştur. Tseng ve arkadaşlarının yapmış olduğu çalışmada dismenorenin tedavisinde gül çayı içmenin yararlı olabileceği bildirilmiştir. ${ }^{28}$ Çalışma sonucumuzda en fazla 
vitamin desteği yönteminin kullanılma nedenleri; vitamin desteğinin ulaşılabilir olması, çalışmamızın sağıı bilimleri fakültesi öğrencileri üzerinde yapılmış olması dolayısıyla öğrencilerin bu konuda bilgi ve farkındalık düzeyinin yüksek olması olabilir. Ayrıca bitkisel yöntemlerin bölgesel ve kültürel farklılıklar gösterebileceği, bu yöntemler konusunda daha fazla çalışmaya ihtiyaç olduğu şeklinde yorum yapılabilir.

Çalışmamıza katılan öğrencilerin PMS'nin yönetiminde; vücut terapilerinden en fazla masaj yöntemini kullandığı, kullananların \%97,8'i fayda sağladığı belirlenmiştir. Moradi ve arkadaşlarının yaptıkları çalışmada 8 hafta boyunca masaj terapi uygulanan PMS tanılı kadınlarda müdahele öncesine göre somatik ve psikolojik şikayetlerin anlamlı derecede azaldığı bildirilmiştir. ${ }^{29}$ Lotfipur-Rafsanjani ve arkadaşlarının PMS yaşayan öğrencilerle yapmış oldukları çalışmada masaj uygulamasının PMS'nin fiziksel, zihinsel, psikolojik belirtilerini azalttığı bulunmuştur. ${ }^{8}$ Hernandez-Reif ve arkadaşlarının yaptığı çalışmada PMS yaşayan kadınlara uygulanan masaj terapiden hemen sonra ağrı, depresif ruh hali ve kaygıda azalma görülmüş, masaj terapi beş hafta süre boyunca yapıldığında ise kadınlarda genel PMS belirtilerinde anlamlı derecede azalma görüldüğü belirlenmiştir. ${ }^{30}$ Çalışmamız literatürdeki sonuçları desteklemektedir. Çalışmamızda öğrencilerin en az $(\% 0,6)$ akupunktur yöntemini kullanmışlardır. Armour ve arkadaşlarının yaptıkları, premenstrual sendrom için akupunktur ve akupresür başlıklı sistematik derlemede sınırlı kanıtlar bulunmakla birlikte akupunktur ve akupresürün PMS'nin hem fiziksel hem de psikolojik semptomlarını iyileştirebileceğini bildirilmiştir. ${ }^{10}$ Shin ve arkadaşlarının yaptıkları çalışmada da el akupunktur tedavisinin PMS yaşayan kadınlarda PMS semptomları yaşama durumunu önemli ölçüde azalttığı bildirilmiştir. ${ }^{31}$ Çalışma sonucumuzda en fazla masaj yönteminin kullanılma nedenleri masajın basit yöntemlerle uygulanabilir olması ve maliyetsiz olması; akupukturun en az kullanılmasının nedenleri ise ulaşılabilirliğinin kısıtlı olması, girişimsel bir uygulama olup kadınların bireysel olarak uygulama yapamayacakları, maliyetli olması ve katılımcıların bilgi eksikliği olabilir.

Öğrenciler PMS'nin yönetiminde kullandıkları zihin ve beden tekniklerine baktığımızda, yüksek oranda müzik dinledikleri ve bu yöntemi kullananların \%75,6'sı fayda sağladığı saptanmıştır. Türkiye'de PMS yönetiminde müzik terapinin etkisini inceleyen çalışmaya rastlanılmamakla birlikte, Endonezya'da Azizah ve arkadaşlarının öğrenciler üzerinde yaptıkları çalışmada, Mozart müzik terapisinin öğrencilerin PMS stres puanlarını anlamlı şekilde azalttığı bildirilmiştir. ${ }^{32}$ Seighalani ve arkadaşlarının İran'da yaptıkları çalışmada da müzik terapi yönteminin PMS tanılı kadınlarda depresyon, anksiyete ve fiziksel saldırganlık üzerinde etkili olduğunu belirtilmiştir. ${ }^{33} \mathrm{Bu}$ noktada çalışmamız literatürü destekler niteliktedir. Araştırmamızda öğrenciler en az hipnoz tekniğini $(\% 3,2)$ kullanmışlardır. Moghtader ve Pakseresht'ın yaptıkları çalışmada, PMS tanısı almış öğrencilere sekiz seans hipnoz terapisi uygulanmış ve hipnozun PMS semptomlarının azaltılması üzerinde anlamlı şekilde etkisi olduğu bildirilmiştir. ${ }^{34}$ Araştırma sonucumuzda en fazla müzik dinlemenin kullanılmasının nedeni; çalışmamızın yürütüldüğü popülasyonun genç popülasyon olması, müziğin katılımcılara çeşitli seçenekler sunabiliyor olması, ulaşılabilir olması; en az hipnoz tekniğinin kullanılmasının nedeni ise hipnozun ulaşılabilirliğinin kısıtlı olması, girişimsel bir uygulama olup kadınların bireysel olarak uygulama yapamayacakları, maliyetli olması ve katılımcıların bilgi eksikliği olabilir.

Araştırmamıza katılan öğrencilerin \%87,7'sinin sıcak uygulama yöntemi olarak karın bölgesine sıcak uygulama yaptığı, \%86,4'ünün ise duş yöntemini kullandığı bulunmuştur. Karın bölgesine sıcak uygulama yapan öğrencilerin \%88,7'sinin yarar gördüğü belirlenmiştir. Literatürdeki çalışmalarda kadınların PMS yönetiminde \%32,3 ile \%75,6 arasında sıcak uygulama yaptıkları bulunmuştur. ${ }^{12,35-38}$ Araştırma sonuçlarımız literatür ile benzerlik göstermektedir. Sıcak uygulamanın; vazodilatasyon sağlaması dolayısıyla kan dolaşımını rahatlatması, bölgesel oksijenlenmeyi sağlaması, metabolizmayı hızlandırması ve metabolizma atık ürünlerinin atılması, ISı reseptörleri aracııı̆ı ile ağrıyı azaltan refleksleri harekete geçirmesi, kaslarda gevşemeyi sağlaması, yara iyileşmesini hızlandırması ve bağ dokusunun esnekliğini arttırması gibi pek çok terapötik etkisi bulunmaktadır. ${ }^{38-40}$ Araştırmamızda yüksek oranda sıcak uygulama yapılıyor olmasının 
nedenleri; sıcak uygulama yöntemlerinin ulaşılabilirliğinin yüksek olması, maliyetsiz olması ve kadınların bireysel olarak bu uygulamaları gerçekleştirebiliyor olmaları olabilir.

\section{Sonuç ve Öneriler}

Çalışma sonucumuzda, öğrencilerin PMSÖ toplam puan ortalaması yüksek olup, \%80,5'inin premenstrual sendrom yaşadıkları bulunmuştur. Öğrencilerin geleneksel ve tamamlayıcı tıp uygulamaları olarak, bitkisel tedavi ve vitamin desteği grubundan en çok vitamin desteği yöntemini; vücut terapilerinden en çok masaj yöntemini; zihin ve beden tekniklerinden en fazla müzik dinlemeyi; sıcak uygulama tekniklerinden en fazla karın bölgesine sıcak uygulama yöntemini kullandıkları belirlenmiştir.

- Öğrencilere PMS ve bu durum ile baş etmek için kullanılan GETAT yöntemleri hakkında eğitim verilerek PMS yaşayan öğrencilerin semptom yönetiminde GETAT kullanmaları konusunda farkındalıklarının artırılması,

- GETAT uygulamaları konusunda hizmet içi eğitimlerle hemşirelerin bilgi düzeyleri ve farkındalıklarının artırılması,

- PMS tanısı almış öğrenciler üzerinde GETAT uygulamalarının etkinliğini değerlendiren randomize kontrollü çalışmalarının sayısının artırılması önerilebilir.

\section{Bilgi}

Çıkar çatışması bulunmamaktadır. Bu çalışmada herhangi bir fon veya destekten yararlanılmamıştır. Makale, Kadın Sağlığında Geleneksel ve Tamamlayııı Tıp Uygulamaları Sempozyumu I: Jinekolojik Sorunlar'da (28-29 Mayıs 2021) online sözlü bildiri olarak sunulmuştur.

Makalemizin veri toplama ve sözlü bildiri olarak sunulması aşamasında katkılarından dolayı; Lokman Hekim Üniversitesi Ebelik Bölümü 3.sınıf öğrencileri Hasret Uçar ve Buse Özkan'a, onların nezdinde çalışmamıza katılan tüm öğrencilere teşekkür ederiz.

\section{Etik Onay}

Lokman Hekim Üniversitesi Girişimsel Olmayan Etik Kurul'undan 27.04.2021 tarih, 2021/059 karar ve 2021061 kod numarası ile etik kurul onayı alınmıştır.

\section{Araştırmacı Katkı Oranı Beyanı}

Didem Şimşek Küçükkelepçe: Fikir/kavram, tasarım, denetleme/danışmanlık, veri toplama ve işleme, makale yazımı, eleştirel inceleme.

Fatma Nur Duman: Fikir/kavram, tasarım, veri toplama ve işleme, analiz ve yorum, kaynak taraması, makale yazımı.

Zehra Gölbaşı: Fikir / kavram, tasarım, denetleme/danışmanlık, eleştirel inceleme.

\section{Kaynaklar}

1. Çetin Sarı H, Erbil N. Premenstrual Sendromda Ağrı Yönetimi. Ordu University Journal of Nursing Studies 2020;3(2):202-210.

2. Gençdoğan B. Premenstrual Sendrom İçin Yeni Bir Ölçek. Türkiye'de Psikiyatri 2006;8(1):81-87.

3. Güvenç G, et al. Premenstrual syndrome and attitudes toward menstruation in a sample of nursing students. J Psyc Obs Gyn. 2012;33(3):106-11.

4. Freeman EW, et al. Concurrent Use Of Oral Contraceptives With Antidepressants For Premenstrual Syndromes. J Clin Psychopharmacol 2001;21(5):540-2.

5. Magon N. Gonadotropin releasing hormone agonists: Expanding vistas. Indian journal of endocrinology and metabolism 2011;15(4):261.

6. World Health Organization. General guidelines for methodologies on research and evaluation of traditional medicine. Geneva: World Health Organization, 2000;1-122. 
7. Karout N, Hawai SM, Altuwaijri S. Prevalence And Pattern Of Menstrual Disorders Among Lebanese Nursing Students. Eastern Mediterranean Health Journal 2012;18(3):346-352.

8. Lotfipur-Rafsanjani SM, et al. Effects of geranium aromatherapy massage on premenstrual syndrome: A clinical trial. International Journal of Preventive Medicine, 2018;9(1):1-14.

9. Uzunçakmak T. Üniversite öğrencilerine uygulanan aromaterapinin premenstruel sendrom ile baş etmeye etkisi. T.C. Gazi Üniversitesi, Sağlık Bilimleri Enstitüsü Doktora Tezi 2016; Ankara, Türkiye.

10. Armour $\mathrm{M}$, et al. Acupuncture and acupressure for premenstrual syndrome." (Review) Cochrane Database of Systematic Reviews, 2018;8(3):1-19.

11. Selçuk KT, Avcı D, Yılmaz FA. The Prevalence of Premenstruel Syndrome Among Nursing Students and Affecting Factors. J Psy Nurs 2014;5(1):98-103.

12. Aş̧̧ı Ö, Gökdemir F, Özcan B. Genç Kızların Premenstrual Ve Menstrual Yakınmalarla Baş Etme Yollarının Belirlenmesi. Uluslararası Hakemli Kadın Hastalıkları Ve Anne Çocuk Sağı̆̆ı̆ Dergisi 2015;03(1):16-29.

13. Daşıkan Z, Saruhan A. Çalışan Hemşirelerde Menstrual Yakınmaların İncelenmesi. Sürekli Tıp Eğitim Dergisi 2014;23(1):1-7.

14. Kırcan N. ve ark. Hemşirelik öğrencilerinde premenstrüel sendrom prevalansı ve yaşam kalitesi ile ilişkisi. Adnan Menderes Üniversitesi Tıp Fakültesi Dergisi 2012;13(1):2-12.

15. Dönmez S, Gümüşsoy S. Hemşirelik Öğrencilerinde Premenstrual Sendromun ve Etkileyen Faktörleri İncelenmesi. Kocaeli Tıp Dergisi 2019;8(2):38-45.

16. Çağlar M, Oskay Ü. Prevalence of Premenstrual Syndrome and Using Traditional and Complementary Medicine Therapies Among Nursing Students. İzmir Katip Çelebi Üniversitesi Sağlık Bilimleri Fakültesi Dergisi 2021;6(2):109-115.

17. Topatan $S$, Kahraman Ş. Premenstrual sendrom yaşayan üniversite öğrencilerinin yaşam kaliteleri ve baş etme yöntemlerinin incelenmesi. Anadolu Hemşirelik ve Sağlık Bilimleri Dergisi 2020;23(1):35-44.

18. Yorulmaz DS, Karadeniz H. Premenstrual Sendrom Yaşayan Üniversite Öğrencilerinin Yakınmalarını Azaltmaya Yönelik Kültürel Uygulamaları. İnönü Üniversitesi Sağlık Hizmetleri Meslek Yüksek Okulu Dergisi 2021;9(2):755-769.

19. Acikgoz A, Dayi A, Binbay T. Prevalence of premenstrual syndrome and its relationship to depressive symptoms in first-year university students. Saudi medical journal 2017;38(11):1125.

20. Aba YA, ve ark. Genç Kadınlarda premenstrual sendrom, fiziksel aktivite ve yaşam kalitesi. Journal of Academic Research in Nursing 2018;4(2):75-82.

21. Shamnani G. et al. Prevalence of premenstrual syndrome and premenstrual dysphoric disorder among medical students and its impact on their academic and social performance. National Journal of Physiology, Pharmacy and Pharmacology 2018;8(8):12051208.

22. Bhuvaneswari K, Rabindran $P$, Bharadwaj $B$. Prevalence of premenstrual syndrome and its impact on quality of life among selected college students in Puducherry. The National medical journal of India 2019;32(1):17.

23. Nagendra Gowda MR, Suryakantha AH. Prevalence of premenstrual syndrome among medical students. National Journal of Community Medicine 2017;8(6):292-294.

24. Erbaş N, Altunbaş N. Bazı Değişkenlere Göre Bir Lisedeki Kız Öğrencilerde Premenstrual Sendrom Şiddetinin Ve Algılanan Stres Düzeyinin Belirlenmesi. Acıbadem Üniversitesi Sağlık Bilimleri Dergisi 2021;12(2):250.

25. Bahrami A. et al. High dose vitamin D supplementation can improve menstrual problems, dysmenorrhea, and premenstrual syndrome in adolescents. Gynecological Endocrinology 2018;34(8):659-663.

26. Dadkhah H, Ebrahimi E, Fathizadeh N. Evaluating the effects of vitamin D and vitamin E supplement on premenstrual syndrome: A randomized, double-blind, controlled trial. Iranian journal of nursing and midwifery research 2016;21(2):159.

27. Karimi Z. et al. Treatment of premenstrual syndrome: appraising the effectiveness of cognitive behavioral therapy in addition to calcium supplement plus vitamin D. PsyCh journal 2018;7(1):41-50.

28. Tseng YF, Chen $\mathrm{CH}$, Yang Y. Rose tea for relief of primary dysmenorrhoea in adolescent: A randomized controlled trial in Taiwan. J Midwifery Womens Health. 2005;3(1):50-51.

29. Moradi M. Assessment of the effects of massage therapy on premenstrual syndrome. Zahedan Journal of Research in Medical Sciences 2011;13(2):20-24.

30. Hernandez-Reif M. et al. Premenstrual symptoms are relieved by massage therapy. Journal of Psychosomatic Obstetrics \& Gynecology 2000;21(1):9-15.

31. Shin KR. et al. The effect of hand acupuncture therapy and hand moxibustion therapy on premenstrual syndrome among Korean women. Western journal of nursing research 2009;31(2):171-186.

32. Azizah FN. The Effectiveness of Progressive Muscle Relaxation and Mozart Music Therapy on Premenstrual Syndrome Stress Scores. Jurnal Kebıdanan 2021;11(1):10-14.

33. Zadbagher Seighalani M. et al. The Effectiveness of Traditional Iranian Music Therapy on Depression, Anxiety, Aggression in PMS Patients. Journal of Psychological Studies 2019;15(3):55-72.

34. Moghtader L, Pakseresht S. Comparison of the Effectiveness of Cognitive-Behavioral Group Therapy with Cognitive Hypnosis on Reducing Depression in Students with Premenstrual Syndrome. Journal of Clinical Nursing and Midwifery 2019;8(2):327-336. 
35. Sharma P. et al. Role of bromocriptine and pyridoxine in premenstrual tension syndrome. Indian J Physiol Pharmacol 2007;51(4):368-74.

36. Potur DC, Kömürcü N. The effects of local low-dose heat application on dysmenorrhea. Journal of pediatric and adolescent gynecology 2014;27(4):216-221.

37. Tufan N. Ebelik ve hemşirelik öğrencilerinin premenstrual sendrom ve nonfarmakolojik yöntemlerine ilişkin bilgi ve tutumlarının değerlendirilmesi. İstanbul Bilim Üniversitesi, Sağlık Bilimleri Enstitüsü Yüksek Lisans Tezi 2019; İstanbul, Türkiye.

38. Mucuk S, Başer M. Doğum ağrısını hafifletmede kullanılan tensel uyarılma yöntemleri. Atatürk Üniversitesi Hemşirelik Yüksekokulu Derg 2009;12(3):61-6.

39. Özveren H. Ağrı kontrolünde farmakolojik olmayan yöntemler. Hacettepe Üniversitesi Sağlık Bilimleri Fakültesi Hemşirelik Derg 2011;18(1):83-92.

40. Dahlen HG. et al. Perineal outcomes and maternal comfort related to the application of perineal warm packs in the second stage of labor: a randomized controlled trial. BIRTH 2007;34(4):282-90. 